Published in final edited form as:

Clin Obstet Gynecol. 2019 March ; 62(1): 142-155. doi:10.1097/GRF.0000000000000414.

\title{
Alcohol Use in Pregnancy
}

\section{KATHERINE DEJONG, MD*, AMY OLYAEI†, JAMIE O. LO, MD*}

\author{
*Department of Obstetrics and Gynecology, Oregon Health and Science University, Portland \\ tDepartment of Microbiology, Oregon State University, Corvallis, Oregon
}

\begin{abstract}
Alcohol exposure during pregnancy results in impaired growth, stillbirth, and fetal alcohol spectrum disorder. Fetal alcohol deficits are lifelong issues with no current treatment or established diagnostic or therapeutic tools to prevent and/or ameliorate some of these adverse outcomes. Despite the recommendation to abstain, almost half of the women consume alcohol in pregnancy in the United States. This review focuses on the trends in prenatal alcohol exposure, implications for maternal and fetal health, and evidence suggesting that preconception and the prenatal period provide a window of opportunity to intervene, mitigate, and ideally curtail the lifetime effects of fetal alcohol spectrum disorder.
\end{abstract}

\section{Keywords}

prenatal alcohol use; fetal alcohol syndrome disorder; fetal alcohol syndrome

\section{Introduction}

Alcohol has had a long-standing role in culture over time in relation to social connectedness and relaxation. However, overconsumption is linked to a multitude of serious health and social problems, including adverse events such as motor vehicle crashes, violence, unemployment, broken relationships, and unstable housing. In the United States, alcohol misuse contributes to 88,000 deaths a year and 1 in 10 deaths in working adults. ${ }^{1}$ Alcohol misuse cost the United States $\$ 223.5$ billion in 2006, with three quarters of the economic cost and half of the reported deaths from binge drinking. ${ }^{2}$ In 2010, the annual cost in the United States had increased to $\$ 250$ billion, with $\$ 5.5$ billion (or $2.2 \%$ of the cost) related to drinking in pregnancy. ${ }^{3}$ Alcohol misuse impacts individuals of all ages, socioeconomic statuses, and races, with some of these individuals also partaking in other illicit substances.

Of concern, alcohol use in pregnancy remains common with the global prevalence of alcohol use in pregnancy from 1984 to 2014 estimated to be $9.8 \%{ }^{4}$ with rates of use varying depending on the country where the woman resides. According to an international multicenter cross-cohort comparison, the rates of alcohol use in pregnancy ranged from $20 \%$

Correspondence: Jamie O. Lo, MD, 3181 SW Sam Jackson Park Road, Mail Code L458, Portland, OR. loj@ ohsu.edu. 
to $80 \%$ in Ireland and $40 \%$ to $80 \%$ in Australia, New Zealand, and the United Kingdom. ${ }^{5}$ In the United States, the prevalence of any alcohol use amongst women 18 to 44 years of age was found to be $53.6 \%$, with the prevalence of binge drinking $18.2 \% .^{6}$ Among pregnant women, the prevalence of any alcohol use was $10.2 \%$ and the prevalence of binge drinking $3.1 \%$, with 1 in 10 of these women reporting alcohol use within the last 30 days and 1 in 33 reporting binge drinking during pregnancy. ${ }^{6}$ The 2002-2009 Pregnancy Risk Assessment Monitoring System data set showed that in that sample, $49.4 \%$ of women reported drinking alcohol before pregnancy and that among these women, $~ 87 \%$ quit during pregnancy, $6.6 \%$ of women reduced their intake, and $6.4 \%$ did not change their intake. ${ }^{7}$

These statistics are in stark contrast with the Surgeon General recommendations in the United States. In 1981, US Surgeon General Edward Brandt advised women who were pregnant or considering pregnancy to limit the amount of alcohol they drank. ${ }^{8}$ In 2005 , Surgeon General Richard Carmona recommended abstinence from alcohol for pregnant women and women who may become pregnant to eliminate the risk of giving birth to an infant affected by fetal alcohol spectrum disorders (FASD). This recommendation was made in the setting of no known safe amount of alcohol in pregnancy. If a woman had already consumed alcohol in pregnancy, the recommendation was to stop to minimize further risk. ${ }^{9}$

Alcohol use in pregnancy poses specific risks to a developing fetus and is linked with adverse perinatal outcomes, which are likely more common than previously reported. Half of all pregnancies in the United States are unintended, ${ }^{10}$ so a fetus may be exposed to alcohol in utero at important times in embryologic development even before a woman knows that she is pregnant. Alcohol use during pregnancy is a leading, preventable cause of birth defects and developmental disabilities in the United States, with fetal alcohol syndrome (FAS) being one of the most severe outcomes. Other adverse health effects associated with alcohol use in pregnancy include miscarriage, preterm labor, intrauterine growth restriction, and stillbirth, which all add morbidity to any potential underlying disability. ${ }^{11,12}$ Alcohol use in reproductive-aged women, and in pregnancy more specifically, remains a public health priority in the United States and abroad. Women are often motivated to make changes in pregnancy and therefore health care providers, especially obstetricians, play an important role in screening, educating, and intervening.

\section{Definitions and Classifications}

\section{STANDARD DRINK}

A standard alcoholic drink can differ in different countries but in the United States and Canada, it is equivalent to $0.6 \mathrm{fL} \mathrm{oz}$ of pure ethanol. ${ }^{13-16}$ This is approximately the amount of ethanol in a $12 \mathrm{oz}$ beer or wine cooler, $5 \mathrm{oz}$ of table wine, 8 to $9 \mathrm{oz}$ malt liquor, or $1.5 \mathrm{oz}$ of $40 \%$ spirit $^{13,14}$ (Table 1).

\section{AT-RISK DRINKING}

The National Institute on Alcohol Abuse and Alcoholism defines at-risk alcohol use for healthy nonpregnant women as $>3$ drinks per occasion or $>7$ drinks per week and any amount of drinking for women who are pregnant or at risk of pregnancy. 


\section{MODERATE OR BINGE DRINKING}

The United States Drug Administration classifies moderate drinking in women as 1 drink per day. ${ }^{13}$ Binge drinking, however, is defined as $>3$ drinks per occasion for women or alcohol consumption that results in a blood alcohol concentration of $0.08 \%$ or above. ${ }^{15}$ Interestingly, almost half of binge drinking occurs in moderate drinkers. ${ }^{17}$

\section{Recommendations for Drinking in Pregnancy}

Alcohol readily crosses the placenta with fetal blood alcohol levels approaching maternal levels within 2 hours of maternal intake. As there is known safe level of alcohol consumption during pregnancy, and alcohol is a known teratogen that can impact fetal growth and development during all stages of pregnancy, the current recommendation from the American College of Obstetricians and Gynecologists, Center for Disease Control (CDC), Surgeon General, and medical societies from other countries including the Society of Obstetricians and Gynecologists of Canada all recommend complete abstinence during pregnancy. ${ }^{14-16,18,19}$

\section{Populations at Greatest Risk}

The 2013 Substance Abuse and Mental Health Services Administration survey found that of women who consume alcohol during pregnancy, those at greatest risk for alcohol use disorder were most likely American Indian and Alaska Native women (13.7\%) compared with white non-Hispanic women (5.6\%), Hispanic or Latino women (3.8\%), and black nonHispanic women (3.5\%). ${ }^{20}$ Interestingly, the CDC surveillance system noted, between 2011 and 2013, that the characteristics associated with the highest prevalence of prenatal alcohol use were age between 35 and 44 (18.6\%), non-Hispanic black (13.9\%), college degree (13\%), and employment (12\%). ${ }^{6}$ These women were also more likely to reduce than quit their alcohol use while women who were black or Hispanic, were overweight or obese or multiparas were more likely to quit than reduce their prenatal alcohol consumption. Interestingly, a pregnant woman reported a higher frequency of binge drinking than nonpregnant women. Of women drinking in late-pregnancy, a previous large survey found that the highest prevalence was among women who are white non-Hispanic, college graduates, and aged 35 years or older. ${ }^{21}$ The hypothesis for these findings was that women who were older and/or more educated had greater discretionary income and those who attended college might have a greater acceptance of alcohol consumption and binge drinking. Unfortunately, these groups of women are also those whom health care providers report having the least screening and counseling for alcohol use. ${ }^{21}$ The presence of social stressors also seemed to correlate with ongoing alcohol use during the third trimester of pregnancy. ${ }^{7}$

In regards to binge drinking during pregnancy, the most significant demographic factor was nonmarried status, likely secondary to a multitude of socioeconomic factors, with a prevalence of 4.6 times greater than married pregnant women. ${ }^{6}$ Of those who binge drank while pregnant, there was a significantly higher frequency of binge drinking (4.6 vs. 3.1 episodes) and greater alcohol consumption per episode ( 7.5 vs. 6 drinks) compared with nonpregnant binge drinkers. ${ }^{6}$ 
Of women who drink in pregnancy, for unclear reasons, there is an increased risk of FAS in those who are of older maternal age, high parity, and African American or Native American ethnicities. ${ }^{19,22}$

\section{Adverse Maternal Outcomes From Alcohol Consumption}

Although men are more likely to drink alcohol and in larger quantities, women have a greater absorption and slower metabolism than men and thus, upon drinking equal amounts, women will have higher blood alcohol levels than men. In addition, women will more likely have long-term health problems from drinking than men $^{23}$ such as liver disease, including cirrhosis, ${ }^{24}$ memory loss, ${ }^{25,26}$ decreased brain volume, ${ }^{25,26}$ cardiomyopathy, ${ }^{27}$ and cancer of the mouth, throat, esophagus, liver, colon, and breast. ${ }^{28-31}$ Women who engage in heavy drinking or chronic alcohol abuse have also been shown to have reduced fertility and a higher rate of menstrual disorders. ${ }^{32-34}$

\section{Fetal and Neonatal Effects of Maternal Alcohol Consumption}

It is challenging to assess a dose-response relationship between the quantity of alcohol consumed prenatally and the effect on fetal and neonatal outcomes. This difficulty stems from the variability in maternal alcohol clearance rates, fetal developmental sensitivity, genetic susceptibility, timing, and duration during pregnancy when alcohol is consumed, and other confounders such as polysubstance abuse or socioeconomic status. Although binge drinking may not be as concerning as chronic heavy alcohol consumption, adverse developmental effects in the fetus can still occur, especially depending on whether the drinking occurred during critical stages of organ formation. ${ }^{35}$ In addition, fetal alcohol metabolism is slower than in the mother so there may be higher levels of alcohol sustained longer in fetal blood than in maternal blood. ${ }^{15,16}$

\section{STRUCTURAL IMPAIRMENTS}

Prenatal alcohol exposure has been associated with multiple fetal structural anomalies including renal, cardiac, craniofacial, and other major malformations. Several characteristic craniofacial abnormalities include short palpebral fissures, a smooth philtrum, and a thin vermillion border of the upper lip. ${ }^{36,37}$ A previous prospective cohort study from Australia examined the association between prenatal alcohol exposure and the craniofacial shape of children at 12 months of age. ${ }^{12}$ Researchers followed and obtained information regarding alcohol consumption in 451 women 3 months before pregnancy and then each trimester with a subsequent 3-dimensional craniofacial assessment of children at 12 months of age. ${ }^{12}$ The study found that low-dose levels of prenatal alcohol can influence fetal craniofacial development but the clinical significance of this finding remains unknown. ${ }^{12}$

\section{BIRTH OUTCOMES}

Previous studies have noted that overall maternal alcohol consumption, including firsttrimester or late-pregnancy use, can be associated with intrauterine growth restriction as well as an increased risk of stillbirth. ${ }^{14,38,39}$ However, the impact of maternal specifically lowdose alcohol consumption on birth outcomes is not well understood. Several previous 
systematic reviews found that it had little or no effect on intrauterine growth restriction, preterm labor, spontaneous abortion, or stillbirth. ${ }^{11,12}$

\section{NEURODEVELOPMENTAL EFFECTS}

It is unclear whether a single binge drinking episode in early gestation, during increased teratogen susceptibility, results in an increased fetal risk or impacts future child development. A previous prospective observational study, conducted over a decade, examined 51 preschool-aged offspring of nonalcohol-dependent women who engaged in 1 to 5 binge drinking episodes during the first trimester and compared them with 51 children not exposed to any teratogens..$^{40}$ Depending on the child's age, abilities and behavior in preschool offspring were assessed using validated scales. The study noted behavioral differences of pre-school-aged children within 3 of 9 scales, specifically a greater degree of disinhibited behavior but no differences in regards to physical, language, or cognitive outcomes. ${ }^{40}$

Although the association between chronic heavy alcohol consumption during pregnancy and adverse neurodevelopmental effects in childhood has been well studied, the effect of lowdose maternal drinking has been more difficult to elucidate. A previous large multinational systematic review from multiple countries, including the United States, England, and Australia, examined the cognitive, mental health, and socioemotional development of 3- to 16-year-old children following pregnancies with maternal low-dose alcohol consumption. The authors reported evidence of subtle long-term cognitive and behavioral effects such as inattention, mental health problems, and difficulties with short-term memory. ${ }^{41} \mathrm{~A}$ different study from Washington state followed children after low-moderate maternal alcohol consumption in pregnancy up to age 18 and found that half of the older children diagnosed with FAS exhibited normal developmental scores as pre-schoolers but by age 10 all had severe brain dysfunction (http://depts.washington.edu/fasdpn/). ${ }^{42}$ Only $10 \%$ of children diagnosed with FAS in this study had attention difficulties by age 5 but $60 \%$ were affected by age 10 and $100 \%$ had severe dysfunction in areas such as language, memory, and activity level (http://depts.washington.edu/fasdpn/). ${ }^{42}$

FASD

The FASD spectrum refers to a group of conditions that can occur in a person whose mother consumed alcohol during pregnancy and has lifelong implications (Fig. 1). Although the prevalence is difficult to assess, the CDC and other studies estimate 0.2 to 7 infants with FASD for every 1000 live births in certain areas of the United States. ${ }^{45,46}$ FAS is considered the most common teratogenically induced, nonhereditary form of mental deficiency throughout the western world. It is associated with reduced intelligence, ${ }^{47}$ attention disorders, ${ }^{48,49}$ neuropsychological deficits, ${ }^{50-53}$ physical abnormalities including facial dysmorphology, ${ }^{15,16}$ sleep disorders, and behavioral problems.

There is no cure for FASD and it is irreversible but it can be completely prevented if women abstain from alcohol consumption while pregnant or when trying to conceive given women often do not recognize they are pregnant until 4 to 6 weeks postconception. ${ }^{54,55}$ 
FAS

This represents the most involved end of the FASD spectrum. Those affected by FAS might have abnormal facial features, growth problems, central nervous system abnormalities, and difficulties with learning, memory, attention span, communication, vision, or hearing. Often, people with FAS have problems in school and trouble socially with others. The global prevalence of FAS in children and youth in the general population has been estimated to be 7.7 per 1000 population. ${ }^{56} \mathrm{~A}$ study aiming to identify the prevalence of FASD among firstgrade students in a representative Midwestern US community estimated that FAS in that community likely ranged from 6 to 9 per 1000 children with the total rate of FASD likely ranging from 24 to 48 per 1000 children. ${ }^{57}$ This study also found that the most predictive maternal risk factors associated with the cognitive, behavioral, and neurodevelopmental effects seen in children with FASD are late recognition of pregnancy, the quantity of alcoholic drinks consumed 3 months before pregnancy and the quantity of drinking reported by the child's father.

\section{ALCOHOL-RELATED NEURODEVELOPMENTAL DISORDER}

People with alcohol-related neurodevelopmental disorder can have intellectual disabilities and issues with behavior and learning. School is often challenging and they have difficulty with math, memory, attention, judgement, and poor impulse control.

\section{ALCOHOL-RELATED BIRTH DEFECTS}

Those with alcohol-related birth defect can have structural abnormalities of the heart, kidneys, and bones. They can also have complications with hearing.

\section{Children With FASD}

It is difficult to diagnose FASD because there is no biological test and other disorders such as attention-deficit/hyperactivity disorder and Williams syndrome have similar symptoms. Diagnosis includes evaluating for features of abnormal facial features, lower-than-average height and/or weight, central nervous system abnormalities (eg, small head circumference, problems with attention and hyperactivity, poor coordination) and prenatal alcohol exposure; although, confirmation of maternal alcohol consumptions is not required to diagnose FASD.

The prevalence of FASD in the United States has been noted to be as high as 1 to 5 per 100 school-aged children with FAS occurring in up to 6 to 9 of 1000 school-aged children. 46,57-59 The cost to the United States for FAS alone, not including people with FASD, is over $\$ 4$ billion annually with the lifetime cost of 1 individual with FAS of $\sim \$ 2$ million in $2002^{46}, 57-59$

Although FASD is irreversible, research has shown that early intervention services, from birth to 3 years of age, can improve a child's development. ${ }^{60-62}$ These interventions include medications to ameliorate symptoms, behavior and education therapy, parent training, and other alternative approaches. ${ }^{60-62}$

Studies have also shown that some protective factors can help mitigate the adverse effects of FASD including diagnosis of FASD before the age of 6, a loving, nurturing, and stable home 
environment during school-age years, the absence of violence, and involvement in special education and social services. ${ }^{60-62}$ When children are diagnosed at a young age, they can then be placed in appropriate educational classes to receive appropriate social services that are geared to their specific needs and learning style. As children with FASD can be more sensitive to disruptions in lifestyle or routine, a stable home life can help prevent secondary conditions, such as criminal behavior, unemployment, and incomplete education that they are at increased risk for.

There is no specific medication approved for the treatment of FASD but there are different types of medications that can alleviate FASD symptoms including stimulants, antidepressants, neuroleptics, and anxiolytics.

\section{NEUROBEHAVIORAL DISORDER ASSOCIATED WITH PRENATAL ALCOHOL EXPOSURE (ND-PAE)}

ND-PAE refers to children exposed prenatally to alcohol that do not satisfy the full criteria for a diagnosis of FAS. This is a recognized condition in the Diagnostic and Statistical Manual 5 of the American Psychiatric Association since 2013. To meet criteria, the mother of the child must have consumed greater than minimal levels of alcohol, $>13$ alcohol drinks per month or $>2$ alcohol drinks in 1 sitting, prenatally. Children diagnosed with ND-PAE have difficulties in 3 areas: (1) thinking and memory; (2) behavior problems; and (3) trouble with day-to-day living. Problems in these areas can include problems with forgetting material learned, severe tantrums, irritable mood, difficulty shifting attention between tasks, playing with other children, and activities of daily living like bathing.

\section{Animal Studies of Prenatal Alcohol Exposure}

Evidence from previous animal studies have found prenatal alcohol exposure to disrupt normal fetal developmental processes through a multitude of mechanisms including disruption of cellular metabolism (ie, oxidative stress, suppression of protein, and DNA synthesis), impairment of cell acquisition, altered gene expression, interference with growth factor signaling, increased cell damage and apoptosis, and altered placental function and hemodynamics resulting in fetal hypoxia. ${ }^{11,63-71}$

A previous nonhuman primate (NHP) study of Rhesus macaques focused on evaluating the effects of chronic early gestation alcohol exposure on placental function and fetal brain development. ${ }^{71}$ Animals were trained to orally self-administer ethanol solution daily throughout the first trimester and all underwent Doppler-ultrasound followed by placental and fetal magnetic resonance imaging (MRI). This study concluded that chronic firsttrimester ethanol exposure significantly reduced placental perfusion and oxygen supply to the fetal vasculature later in pregnancy. ${ }^{71}$ These perturbations of placental function were associated with impaired fetal weight and brain development. Specifically, ethanol-exposed NHP fetuses showed significantly smaller fetal biparietal diameter and brain weight, consistent with previous MRI studies in murine ${ }^{72}$ and rat models ${ }^{73,74}$ showing structural brain abnormalities from first-trimester ethanol exposure and microcephaly that is routinely observed with FAS in human neonates. ${ }^{75}$ In addition, $\mathrm{T}_{2}$-weighted MRI images of the NHP 
fetal brain to measure brain volume and surface area was indicative of impaired growth and development. ${ }^{71}$

In addition, another NHP study simulated a once-per-week human binge drinking pattern and showed an increase in fetal facial anomalies, growth deficiency, and central nervous system dysfunction. ${ }^{76}$ Even in animals without structural anomalies, behavioral abnormalities were observed. ${ }^{77}$ A different NHP study followed offspring for the first 24 months of life who had been exposed in utero to once weekly maternal ethanol consumption continued through the first versus second versus third trimester. ${ }^{77}$ This study found that fetuses exposed to alcohol earlier in gestation were associated with more severe and debilitating cognitive abnormalities than those with later exposure in pregnancy. ${ }^{77}$ Other animal studies evaluating the effects of a single binge drinking incident prenatally have shown fetal neurotoxic effects. ${ }^{78-80}$

\section{Recognization and Screening PRACTICED-BASED SCREENING}

Previous studies have shown that even low levels of prenatal alcohol exposure can negatively affect the developing fetus ${ }^{81-84}$ and the earlier in pregnancy women can stop drinking, the better the outcome ${ }^{85}$; thus, there is increasing importance to identify women who drink during pregnancy. Screening all women of childbearing age and those who are pregnant regarding their alcohol consumption is a practical process to identify women at risk for maternal drinking for earlier recognition of potentially exposed fetuses and to diagnose FASD sooner. This can result in a reduction of primary FASD disabilities as well as secondary disabilities often related to FASD in the absence of diagnosis.

\section{STRUCTURED QUESTIONNAIRES}

Structured questionnaires can also be used to screen pregnant women for alcohol use but this can be challenging because traditional alcohol-screening questionnaires such as the Michigan Alcoholism Screening Test (MAST) ${ }^{86}$ and the CAGE screening instrument ${ }^{87}$ are less effective in identifying drinking problems among women compared with men. This is secondary to the biological differences between women and men as well as different patterns of alcohol consumption and thresholds for problem drinking. As such, there are newer brief alcohol-screening questionnaires designed specifically for the prenatal setting and of those, T-ACE has the highest at-risk drinking sensitivity (69\% to $88 \%$ ). ${ }^{88,89}$ However, a limitation of screening questionnaires is that there is underreporting bias of maternal alcohol consumption due to inaccurate patient recall, embarrassment, or denial regarding actual consumption. ${ }^{90-93}$

\section{LABORATORY-BASED SCREENING}

At this time, there is no laboratory test that can definitively detect and quantify prenatal alcohol use. ${ }^{94}$ Current laboratory testing is limited by the short half-life of alcohol in the blood stream making it difficult to detect; negative results do not rule out alcohol use and a positive test fails to reveal a pattern of alcohol use. Traditionally, maternal and neonatal urine and blood samples have been used to determine prenatal alcohol use. ${ }^{95,96}$ However, the 
biomarkers measured from these samples mostly reflect alcohol exposure within 2 to 3 days before delivery. Other samples such as amniotic fluid, umbilical cord blood, neonatal hair, placenta, breast milk, vernix, or meconium have also been considered. Meconium, often used to detect prenatal exposure to drugs, has been studied to measure fatty acid ethyl esters (FAEE) as a biomarker for prenatal alcohol use that may reflect exposure since the 13th week of pregnancy when meconium first begins to form. ${ }^{94,97-99}$ However, the correlation between FAEE in meconium and prenatal alcohol use is not perfect ${ }^{94,98}$ as it may accumulate unevenly in meconium over time and there are genetic variations in alcohol metabolism that may influence the synthesis of FAEE, and illness, medications, or food additives can affect FAEE concentrations. A previous study examining the benefits of universal meconium screening for maternal drinking during pregnancy found that such screening is premature and would only be effective if a societal willingness to institute prevention and intervention programs to improve women and children's health was in place. 100

\section{Interventions for Women to Stop Drinking}

Maternal substance use remains highly stigmatized, thus making pregnant women more reluctant to disclose problems associated with their substance use when attempting to use services. ${ }^{101}$ Brief interventions are a collection of time-limited counseling strategies geared toward facilitating the reduction or elimination of at-risk alcohol use in patients. Three components to a more successful brief intervention are: (1) assessment and feedback after assessment; (2) advice and discussion of strategies for reducing or eliminating problematic alcohol use; and (3) assistance in the form of eliciting ideas about change strategies, goal setting, positive reinforcement, and referrals to supportive services. ${ }^{102}$ Strong evidence exists to that brief behavioral counseling interventions occurring preconception, prenatally, or postpartum can reduce the incidence of alcohol-exposed pregnancy in women who engage in at-risk drinking. ${ }^{15,16,103} \mathrm{~A}$ previous study reported that pregnant women in the brief intervention group were 5 times more likely than women in the control group to have reported that they abstained from alcohol. ${ }^{103}$ The most common form of brief intervention in pregnant women is motivational interviewing, which motivates individuals to change behaviors through exploring and resolving discrepancy and ambivalence. It has been specifically effective in helping women who are drinking problematically prevent an alcohol-exposed pregnancy.

Harm reduction is another approach that has been found to be helpful in assisting women to reduce harms associated with substance use and with establishing realistic and attainable goals to decrease their alcohol consumption while working toward abstinence. This method strives to shift away from stigma, guilt, confrontation, and shame but instead works toward empowerment.

Pregnant women who are alcohol dependent are more likely to have difficulties quitting than those without dependency problems and thus need specialized counseling and more intense support. They are also more likely to have a wide range of other health problems that may need attention as most often alcohol problems and dependency are symptomatic of 
underlying social and emotional difficulties. ${ }^{15,16,104}$ In this setting, home-visiting advocacy has been shown to be helpful. ${ }^{105,106}$

\section{Pregnancy Management}

As comprehensive prenatal care can mitigate some of the maternal, fetal, and neonatal complications secondary to maternal alcohol abuse, it is recommended that health care providers should screen all pregnant women for alcohol use, counsel pregnant women regarding the risks of alcohol consumption, assemble a multidisciplinary team of medical and social service providers to comprehensively assess women with alcohol abuse and their offspring, schedule frequent prenatal visits for antenatal surveillance of maternal and fetal status, provide pregnant women with education and support, and obtain an early dating ultrasound to more accurately follow fetal growth throughout gestation. ${ }^{107}$

\section{Alcohol Use While Breastfeeding}

Many studies have documented the harmful effects of alcohol consumption during pregnancy; however, there are limited data on the impact of maternal alcohol consumption while breastfeeding. It has been reported that the concentration of alcohol in breast milk is similar to that of maternal blood concentration. ${ }^{108}$ Alcohol has the ability to freely pass through a lactating mother's milk and thus lactating mothers who decide to continue to drink should avoid breastfeeding 3 to 4 hours after moderate to high consumption of alcohol. ${ }^{108}$ At moderated doses of alcohol consumption (1 to 2 drinks), there are negligible amounts of alcohol present within a lactating mother's milk thus making it less harmful for a mother to breastfeed their infant. ${ }^{109}$

This is of concern because among women who consume alcohol during the pregnancy, the majority continues to drink throughout their lactation period. It has been reported that $35 \%$ to $80 \%$ of mothers consume alcohol during lactation, ${ }^{110}$ but of concern a study showed that only $13 \%$ of lactating mothers reported receiving advice from their primary health care provider about the detrimental effects of drinking while breastfeeding. ${ }^{111}$ This collectively suggests a lack of uniform communication between health care providers and their patients about the risks of alcohol consumption throughout lactation.

Alcohol consumption can also significantly impact the neuroendocrine state of a mother and as a result, a decreased ability to breastfeed. Two major hormones play a vital role in breastfeeding: oxytocin, which is essential for contraction of mammary glands, and prolactin, which stimulates the production of breast milk. ${ }^{12}$ A number of studies have found that alcohol consumption while lactating decreases both these hormones. One specific study showed a $>75 \%$ decrease in oxytocin levels after alcohol consumption. ${ }^{12}$ Previous studies have also shown that a nursing infant consumes significantly less milk after maternal alcohol consumption, mostly because of a lack of milk production rather than palatability. ${ }^{113}$

Although there are limited data regarding the impact of maternal alcohol consumption on breastfeeding infants, it is associated with increased adverse effects on the offspring. A previous study examining the effect of alcohol consumption during lactation in 400 infants reported a significant reduction in psychomotor index in infants exposed to alcohol during 
lactation. They also established a dose-response and reduction in psychomotor index. Furthermore, it has been previously reported that consumption of alcohol can impose intellectual deficiencies such as attention-deficit hyperactivity disorder ${ }^{114}$ and affect infant sleep patterns. In a small clinical study, mothers of 23 infants consumed moderate amounts of alcohol 3 hours before nursing and the sleep patterns of the infants were monitored for the next 24 hours. ${ }^{112}$ This study revealed that the infants' sleep patterns were affected when alcohol was consumed by their mothers 3 hours before the infant falling asleep.

\section{Conclusions}

FAS disorder spectrum and other adverse fetal effects secondary to maternal alcohol consumption prenatal alcohol exposure will continue to be a substantial public health concern and afflict future generations without successful prevention, intervention, and management. The times before, during and after pregnancy are all critical periods for maternal alcohol consumption awareness, reduction, and ideally abstinence. An increased awareness among the general public and health care providers combined with effective universal prevention strategies and improved guidelines for the detection, prevention, and management of FASD, are important measures in addressing this ongoing concern. Although preconception alcohol cessation is preferred, this recommendation is unavailable to at least $30 \%$ to $50 \%$ of women whom pregnancies are unplanned. ${ }^{10}$ Pregnancy is a unique time when women are motivated to adopt healthy behaviors that may potentially benefit their child. Knowing that fetal alcohol exposure is the most common nongenetic cause of cognitive impairment, it is critical to identify maternal alcohol consumption early as a primary target to prevent downstream FASD. Therefore, innovative research studies are vital to better understand the mechanism of alcohol on pregnancy to then target the development of therapeutic strategies to mitigate its adverse effects and improve maternal and fetal outcomes.

\section{References}

1. Stahre M, Roeber J, Kanny D, et al. Contribution of excessive alcohol consumption to deaths and years of potential life lost in the United States. Prev Chronic Dis. 2014;11:E109. [PubMed: 24967831]

2. Bouchery EE, Harwood HJ, Sacks JJ, et al. Economic costs of excessive alcohol consumption in the US, 2006. Am J Prev Med. 2011;41: 516-524. [PubMed: 22011424]

3. Sacks J, Gonzales K, Bouchery E, et al. 2010 national and state costs of excessive alcohol consumption. Am J Prev Med. 2015;49:e73-e79. [PubMed: 26477807]

4. Popova S, Lange S, Probst C, et al. Estimation of national, regional, and global prevalence of alcohol use during pregnancy and fetal alcohol syndrome: a systematic review and meta-analysis. Lancet Glob Health. 2017;5:e290-e299. [PubMed: 28089487]

5. O'Keeffe LM, Kearney PM, McCarthy FP, et al. Prevalence and predictors of alcohol use during pregnancy: findings from international multicentre cohort studies. BMJ Open. 2015;5: e006323.

6. Tan $\mathrm{CH}$, Denny $\mathrm{CH}$, Cheal NE, et al. Alcohol use and binge drinking among women of childbearing age-United States, 2011-2013. MMWR Morb Mortal Wkly Rep. 2015;64:1042-1046. [PubMed: 26401713]

7. Kitsantas P, Gaffney K, Wu H, et al. Determinants of alcohol cessation, reduction and no reduction during pregnancy. Arch Gynecol Obstet. 2014;289:771-779. [PubMed: 24150521]

8. Office of the Surgeon General (US) Surgeon General's advisory on alcohol and pregnancy. FDA Drug Bull. 1981;11:9-10. [PubMed: 7250574] 
9. Office of the Surgeon General (US). US Surgeon General releases advisory on alcohol use in pregnancy. 2005 Available at: http://come-over.to/FAS/SurGenAdvisory.htm Accessed July 1, 2018.

10. Finer LB, Zolna MR. Unintended pregnancy in the United States: incidence and disparities, 2006. Contraception. 2011;84:478-485. [PubMed: 22018121]

11. Henderson J, Gray R, Brocklehurst P. Systematic review of effects of low-moderate prenatal alcohol exposure on pregnancy outcome. BJOG. 2007;1114:243-252.

12. Muggli E, Matthews H, Penington A, et al. Association between prenatal alcohol exposure and craniofacial shape of children at 12 months of age. JAMA Pediatr. 2017;171:771-780. [PubMed: 28586842]

13. Bowman SA, Clemens JC, Friday JE, et al. Food Patterns Equivalents Database 2011-12: methodology and user guide. Food Surveys Research Group, Beltsville Human Nutrition Research Center, Agricultural Research Service, US Department of Agriculture, Beltsville, Maryland 2014 Available at: www.ars.usda.gov/nea/bhnrc/fsrg Accessed June 18, 2018.

14. American College of Obstetricians and Gynecologists. Committee on Health Care for Underserved Women. Committee opinion no. 496: at-risk drinking and alcohol dependence obstetric and gynecologic implications. Obstet Gynecol. 2011; 118(pt 1):383-388. [PubMed: 21775870]

15. Carson G, Cox LV, Crane J, et al. Alcohol use and pregnancy consensus clinical guidelines. Society of Obstetricians and Gynecologists of Canada. J Obstet Gynaecol Can. 2010;32(suppl 3):S1-S31.

16. Carson G, Cox LV, Crane J, et al. No. 245-Alcohol use and pregnancy consensus clinical guidelines. J Obstet Gynaecol Can. 2017;39:e220-e254. [PubMed: 28859770]

17. Naimi TS, Lipscomb LE, Brewer RD, et al. Binge drinking in the preconception period and the risk of unintended pregnancy: implications for women and their children. Pediatrics. 2003; 111(pt 2):1136-1141. [PubMed: 12728126]

18. Williams JF, Smith VC. Committee on substance abuse. Fetal alcohol spectrum disorders. Pediatrics. 2015;136:e1395-e1406. [PubMed: 26482673]

19. Centers for disease control and prevention: fetal alcohol spectrum disorders (FASDs). 2018 Available at: www.cdc.gov/ncbddd/fasd/alcohol-use.html Accessed June 18, 2018.

20. Substance Abuse and Mental Health Services Administration, Results From the 2013 National Survey on Drug Use and Health: Mental Health Findings, NSDUH Series H-49, HHS Publication No (SMA) 14-4887. Rockville, MD: Substance Abuse and Mental Health Services Administration; 2014 Available at: www.samhsa.gov/data/sites/default/files/ NSDUHresultsPDFWHTML2013/Web/NSDUHresults2013.pdf Accessed June 18, 2018.

21. Cheng D, Kettinger L, Uduhiri K, et al. Alcohol consumption during pregnancy: prevalence and provider assessment. Obstet Gynecol. 2011;117 (pt 1):212-217. [PubMed: 21252732]

22. Floyd RL, O'Connor MJ, Sokol RJ, et al. Recognition and prevention of fetal alcohol syndrome. Obstet Gynecol. 2005;106(pt 1): 1059-1064. [PubMed: 16260526]

23. Ashley MJ, Olin JS, le Riche WH, et al. Morbidity in alcoholics. Evidence for accelerated development of physical disease in women. Arch Intern Med. 1977;137:883-887. [PubMed: 879927]

24. Loft S, Olesen KL, Dossing M. Increased susceptibility to liver disease in relation to alcohol consumption in women. Scand J Gastroenterol. 1987;22:1251-1256. [PubMed: 3433014]

25. Hommer DW, Momenan R, Kaiser E, et al. Evidence for a gender-related effect of alcoholism on brain volumes. Am J Psychiatry. 2001;158: 198-204. [PubMed: 11156801]

26. Mann K, Batra A, Gunthner A, et al. Do women develop alcoholic brain damage more readily than men? Alcohol Clin Exp Res. 1992;16: 1052-1056. [PubMed: 1471759]

27. Urbano-Marquez A, Estruch R, Fernandez-Sola J, et al. The greater risk of alcoholic cardiomyopathy and myopathy in women compared with men. JAMA. 1995;274:149-154. [PubMed: 7596003]

28. Smith-Warner SA, Spiegelman D, Yaun SS, et al. Alcohol and breast cancer in women: a pooled analysis of cohort studies. JAMA. 1998; 279:535-540. [PubMed: 9480365]

29. Baan R, Straif K, Grosse Y, et al. Carcinogenicity of alcoholic beverages. Lancet Oncol. 2007; 8:292-293. [PubMed: 17431955]

30. Thun MJ, Peto R, Lopez AD, et al. Alcohol consumption and mortality among middle-aged and elderly US adults. N Engl J Med. 1997;337: 1705-1714. [PubMed: 9392695] 
31. Department of Health and Human Services. Tenth special report to the US Congress on alcohol and health. Bethesda, MD: National Institutes on Alcohol Abuse and Alcoholism 2000 Available at: https://pubs.niaaa.nih.gov/publications/10report/intro.pdf Accessed July 1, 2018.

32. Royal College of Obstetricians and Gynaecologists. Alcohol Consumption and the Outcomes of Pregnancy. London: Royal College of Obstetricians and Gynaecologists; 2006.

33. Sharma R, Biedenharn KR, Fedor JM, et al. Lifestyle factors and reproductive health: taking control of your fertility. Reprod Biol Endocrinol. 2013;16:66.

34. Jensen TK, Holland NHI, Henriksen TB, et al. Does moderate alcohol consumption affect fertility? Follow up study among couples planning first pregnancy. BMJ. 1998;317:505-510. [PubMed: 9712595]

35. Alledeck P, Olsen J. Alcohol and fetal damage. Alcohol Clin Exp Res. 1998;22(suppl): 329S332S. [PubMed: 9799957]

36. Jones KL, Smith DW, Ulleland CN, et al. Pattern of malformation in offspring of chronic alcoholic mothers. Lancet. 1973;1:1267-1271. [PubMed: 4126070]

37. Streissguth AP, Aase JM, Clarren SK, et al. Fetal alcohol syndrome in adolescents and adults. JAMA. 1991;265:1961-1967. [PubMed: 2008025]

38. O'Leary CM, Nassar N, Kurinczuk JJ, et al. The effect of maternal alcohol consumption on fetal growth. BJOG. 2009;116:390-400. [PubMed: 19187371]

39. Patra J, Bakker R, Irving H, et al. Dose-response relationship between alcohol consumption before and during pregnancy and the risks of low birthweight, preterm birth and small for gestational age (SGA) — a systematic review and meta-analyses. BJOG. 2011;118:1411-1421. [PubMed: 21729235]

40. Nulman I, Rover J, Kennedy D, et al. Binge alcohol consumption by non-alcohol dependent women during pregnancy affects child behavior, but not general intellectual functioning; a prospective controlled study. Arch Women's Ment Health. 2004;7:173-181. [PubMed: 15241663]

41. The Swedish National Institute of Public Health. Low dose alcohol exposure during does it harm? A systematic literature review. Stockholm: Stromberg; 2009 Available at: www.euro.who.int/en/ data-and-evidence/evidence-informed-policy-making/publications/hen-summaries-of-networkmembers-reports/is-low-dose-alcohol-exposure-during-pregnancy-harmful Accessed July 1, 2018.

42. Astley S, Grant T Alcohol and pregnancy: another perspective on the disputed Danish Studies. 2012 Available at: http://depts.washington.edu/fasdpn/pdfs/astley-grant-Washington.pdf Accessed July 1, 2018.

43. Streissguth AP, Barr HM, Kogan J et al., Understanding the occurrence of secondary disabilities in clients with fetal alcohol syndrome (FAS) and fetal alcohol effects (FAE) Final Report to the Centers for Disease Control and Prevention (CDC). University of Washington, Fetal Alcohol \& Drug Unit Seattle 1996 Tech. Rep. No. 96-06.

44. Streissguth AP, Bookstein FL, Barr HM, et al. Risk factors for adverse life outcomes in fetal alcohol syndrome and fetal alcohol effects. J Dev Behav Pediatr. 2004;5:228-238.

45. Center for Disease Control (CDC). Fetal alcohol syndrome-Alaska, Arizona, Colorado, and New York, 1995-1997. MMWR Morb Mortal Wkly Rep. 2002;51:433-435. [PubMed: 12056499]

46. May P, Gossage J, Kalberg W, et al. Prevalence and epidemiologic characteristics of FASD from various research methods with an emphasis on recent in-school studies. Dev Disabil Res Rev. 2009;15:176-192. [PubMed: 19731384]

47. Conry J Neuropsychological deficits in foetal alcohol syndrome and foetal alcohol effects. Alcohol Clin Exp Res. 1990;14:650-655. [PubMed: 2264592]

48. Nanson JL, Hiscock M. Attention deficits in children exposed to alcohol prenatally. Alcohol Clin Exp Res. 1990;14:656-661. [PubMed: 2264593]

49. Coles CD, Platzman KA, Raskind-Hood CL, et al. A comparison of children affected by prenatal alcohol exposure and attention deficit, hyperactivity disorder. Alcohol Clin Exp Res. 1997;21:150161. [PubMed: 9046388]

50. Kaemingk K, Paquette A. Effects of prenatal alcohol exposure on neuropsychological functioning. Devel Neuropsychol. 1999;15:111-140.

51. Mattson S, Riley E, Sowell E, et al. A decrease in size of the basil ganglia in children with fetal alcohol syndrome. Alcohol Clin Exp Res. 1996;20: 1088-1093. [PubMed: 8892532] 
52. Kodituwakku PW, May PA, Clericuzio CL, et al. Emotion-related learning in individuals prenatally exposed to alcohol: an investigation of the relation between set shifting, extinction of responses, and behavior. Neuropsychologia. 2001;39:699-708. [PubMed: 11311300]

53. Kodituwakku PW, Kalberg W, May PA. Effects of prenatal alcohol exposure on executive functioning. Alcohol Res Health. 2001;25:192-198. [PubMed: 11810957]

54. Edwards EM, Werler MM. Alcohol consumption and time to recognition of pregnancy. Matern Child Health J. 2006;10:467-472. [PubMed: 16763772]

55. Floyd RL, Decoufle P, Hungerford DW. Alcohol use prior to pregnancy recognition. Am J Prev Med. 1999;17:101-107. [PubMed: 10490051]

56. Lange S, Probst C, Gmel G, et al. Global prevalence of fetal alcohol spectrum disorder among children and youth: a systematic review and meta-analysis. JAMA Pediatr. 2017; 171: 948-956. [PubMed: 28828483]

57. May PA, Baete A, Russo J, et al. Prevalence and characteristics of fetal alcohol spectrum disorders. Pediatrics. 2014;134:855-866. [PubMed: 25349310]

58. Center for Disease Control (CDC). Fetal alcohol syndrome among children aged 7-9 yearsArizona, Colorado, and New York, 2010. MMWR Morb Mortal Wkly Rep. 2015;64:54-57. [PubMed: 25632951]

59. May PA, Chambers CD, Kalberg WO, et al. Prevalence of fetal alcohol spectrum disorders in 4 US communities. JAMA. 2018;319:474-482. [PubMed: 29411031]

60. O'Connor MJ, Frankel F, Paley B, et al. A controlled social skills training for children with fetal alcohol spectrum disorders. J Consult Clin Psychol. 2006;74:639-648. [PubMed: 16881771]

61. Kable JA, Coles CD, Taddeo E. Socio-cognitive habilitation using the math interactive learning experience program for alcohol affected children. Alcohol Clin Exp Res. 2007;31:1425-1434. [PubMed: 17550365]

62. Wells AM, Chasnoff IJ, Schmidt CA, et al. Neurocognitive habilitation therapy for children with fetal alcohol spectrum disorders: an adaptation of the Alert Program. Am J Occup Ther. 2012;66:24-34. [PubMed: 22251828]

63. Mukherjee RAS, Hollins S, Turk J. Fetal alcohol spectrum disorder: an overview. J R Soc Med. 2006;99:298-302. [PubMed: 16738372]

64. Welch-Carre E The neurodevelopmental consequences of prenatal alcohol exposure. Adv Neonatal Care. 2005;5:217-229. [PubMed: 16084479]

65. Goodlett CR, Horn KH. Mechanisms of alcohol-induced damage to the developing nervous system. Alcohol Res Health. 2001;25:175-184. [PubMed: 11810955]

66. Goodlett CR, Horn KH, Zhou FC. Alcohol teratogenesis: mechanisms of damage and strategies for intervention. Exp Biol Med. 2005;230:394-406.

67. Perkins A, Lehmann C, Lawrence RC, et al. Alcohol exposure during development: impact on the epigenome. Int J Dev Neurosci. 2013;31:391-397. [PubMed: 23542005]

68. Khalid O, Kim JJ, Kim HS, et al. Gene expression signatures affected by alcohol-induced DNA methylomic deregulation in human embryonic stem cells. Stem Cell Res. 2014;12:791-806. [PubMed: 24751885]

69. Ungerer M, Knezovich J, Ramsay M. In utero alcohol exposure, epigenetic changes, and their consequences. Alcohol Res. 2013;35:37-46. [PubMed: 24313163]

70. Lui S, Jones RL, Robinson NJ, et al. Detrimental effects of ethanol and its metabolite acetaldehyde, on first trimester human placental cell turnover and function. PLoS One. 2014;9:e87328. [PubMed: 24503565]

71. Lo JO, Schabel MC, Roberts VHJ, et al. First trimester alcohol exposure alters placental perfusion and fetal oxygen availability affecting fetal growth and development in a non-human primate model. Am J Obstet Gynecol. 2017;216:302.e1-302.e8. [PubMed: 28153658]

72. Parnell SE, Holloway HE, Baker LK, et al. Dysmorphogenic effects of first trimester-equivalent ethanol exposure in mice: a magnetic resonance microscopy-based study. Alcohol Clin Exp Res. 2014;38:2008-2014. [PubMed: 24931007]

73. Leigland LA, Ford MM, Lerch JP, et al. The influence of fetal ethanol exposure on subsequent development of the cerebral cortex as revealed by magnetic resonance imaging. Alcohol Clin Exp Res. 2013;37:924-932. [PubMed: 23442156] 
74. Leigland LA, Budde MD, Cornea A, et al. Diffusion MRI of the developing cerebral cortical gray matter can be used to detect abnormalities in tissue microstructure associated with fetal ethanol exposure. Neuroimage. 2013;83:1081-1087. [PubMed: 23921100]

75. American Academy of Pediatrics. Committee on substance abuse and committee on children with disabilities. Fetal alcohol syndrome and alcohol-related neurodevelopmental disorders. Pediatrics. 2000;106(2Pt 1):358-361. [PubMed: 10920168]

76. Clarren SK, Smith DW. Fetal alcohol syndrome. N Engl J Med. 1978;298:1063-1067. [PubMed: 347295]

77. Clarren SK, Astley SJ. Pregnancy outcomes after weekly oral administration of ethanol during gestation in the pig-tailed macaque: comparing early gestational exposure to full gestational exposure. Teratology. 1992;45:1-9. [PubMed: 1731392]

78. Bonthius DJ, West JR. Alcohol-induced neuronal loss in developing rats: increased brain damage with binge exposure. Alcohol Clin Exp Res. 1990;14:107-118. [PubMed: 1689970]

79. West JR, Kelly SI, Pierce DR. Severity of alcohol-induced deficits in rats during the first trimester equivalent is determined by the pattern of exposure. Alcohol Alcohol Suppl. 1987;1:461-465. [PubMed: 3426716]

80. West JR, Goodlett CR, Bonthius DJ, et al. Cell population depletion associated with fetal alcohol brain damage: mechanisms of BAC-dependent cell loss. Alcohol Clin Exp Res. 1998; 14:813-818.

81. Charness ME, Safran RM, Perides G. Ethanol inhibits neural cell-adhesion. J Biol Chem. 1994; 269:9304-9309. [PubMed: 8132668]

82. Ikonomidou C, Bittigau P, Ishimaur M, et al. Ethanol-induced apoptotic neurodegeneration and fetal alcohol syndrome. Science. 2000;287: 1056-1060. [PubMed: 10669420]

83. Jacobson JL, Jacobson SW. Prenatal alcohol exposure and neurobehavioral development. Alcohol Health Res World. 1994;18:30-36. [PubMed: 31798162]

84. Wong EV, Kenwrick S, Willems P, et al. Mutations in cell adhesion molecule L1 cause mental retardation. Trends Neurosci. 1995;18:168-172. [PubMed: 7778187]

85. Barr H, Streissguth AP. Identifying maternal self-reported alcohol use associated with fetal alcohol spectrum disorders. Alcohol Clin Exp Res. 2001;25:283-287. [PubMed: 11236844]

86. Selzer ML. The Michigan Alcoholism Screening Test: the quest for a new diagnostic instrument. Am J Psychiatry. 1971;127:1653-1658. [PubMed: 5565851]

87. Ewing JA. Detecting alcoholism: The CAGE Questionnaire. JAMA. 1984;252:1905-1907. [PubMed: 6471323]

88. Burns E, Gray R, Smith LA. Brief screening questionnaires to identify problem drinking during pregnancy: a systematic review. Addiction. 2010;105:601-614. [PubMed: 20403013]

89. Sokol RJ, Martier SS, Ager JW. The T-ACE questions: practical prenatal detection of risk-drinking. Am J Obstet Gynecol. 1989;160: 863-868. [PubMed: 2712118]

90. Chang G Alcohol-screening instruments for pregnant women. Alcohol Res Health. 2001;24:204209.

91. Morrow-Tlucak M, Ernhart CB, Sokol RJ, et al. Underreporting of alcohol use in pregnancy: relationship to alcohol. Alcohol Clin Exp Res. 1989;13:399-401. [PubMed: 2665555]

92. Verkerk PH. The impact of alcohol misclassification on the relationship between alcohol and pregnancy outcome. Int J Epidemiol. 1992;21(suppl 1):S33-S37. [PubMed: 1399217]

93. Jacobson SW, Jacobson JL, Sokol RJ, et al. Maternal recall of alcohol, cocaine, and marijuana use during pregnancy. Neurotoxicol Teratol. 1991;13:535-540. [PubMed: 1758408]

94. Bearer CF, Jacobson JL, Jacobson SW, et al. Validation of a new biomarker of fetal exposure to alcohol. J Pediatr. 2003;143:463-469. [PubMed: 14571221]

95. Wisniewski KE, Pullarkat RK, Harin A, et al. Increased urinary dolichol in newborns whose mothers were heavy alcohol users. Ann Neurol. 1983;14:382A.

96. Halmesmaki E, Roine R, Salaspuro M. Gamma-glutamyltransferase, aspartate and alanine aminotransferases and their ratio, mean cell volume and urinary dolichol in pregnant alcohol abusers. Br J Obstet Gynaecol. 1992;99:287-291. [PubMed: 1349817]

97. Bearer CF, Lee S, Salvator AE, et al. Ethyl linoleate in meconium: a biomarker for prenatal ethanol exposure. Alcohol Clin Exp Res. 1999;23: 487-493. [PubMed: 10195823] 
98. Chan D, Bar-oz B, Pellerin B, et al. Population baseline of meconium fatty acid ethyl esters among infants of nondrinking women in Jerusalem and Toronto. Ther Drug Monit. 2003; 25:271-278. [PubMed: 12766552]

99. Niemela O, Halmesmaki E, Ylikorkala O. Hemoglobin-acetaldehyde adducts are elevated in women carrying alcohol-damaged fetuses. Alcohol Clin Exp Res. 1991;15:1007-1010. [PubMed: 1789375]

100. Gifford AE, Farkas KJ, Jackson LW, et al. Universal screen for maternal alcohol use during pregnancy. Birth Defects Res A Clin Mol Teratol. 2010;88:838-846. [PubMed: 20890939]

101. United Nations Office on Drugs and Crime (UNODC). Substance Abuse Treatment and Care for Women: Case Studies and Lessons Learned Drug Abuse Treatment Toolkit Series. Vienna: UNODC; 2004.

102. Wilk A, Jensen NM, Havighurstt TC. Meta-analysis of randomized control trials addressing brief interventions in heavy alcohol drinkers. J Gen Intern Med. 1997;12:274-283. [PubMed: 9159696]

103. O'Connor MJ, Whaley SE. Brief intervention for alcohol use by pregnant women. Am J Public Health. 2007;97:252-258. [PubMed: 17194863]

104. National Institute on Alcohol Abuse and Alcoholism (NIAAA). Alcohol: a women's health issue. US Department of Health and Social Services. 2017 Available at: https://pubs.niaaa.nih.gov/ publications/womensfact/womensfact.htm Accessed December 10, 2018.

105. Motz M, Leslie M, Pepler DJ, et al. Breaking the cycle: measures in progress 1995-2005: hospital for sick children. J FAS Int. 2006;4(suppl):e22.

106. Grant TM, Ernst CC, Streissguth A, et al. Preventing alcohol and drug exposed births in Washington state: intervention findings from three parent-child assistance program sites. Am J Drug Alcohol Abuse. 2005;31:471-490. [PubMed: 16161730]

107. American College of Obstetricians and Gynecologists. Special Issues in Women's Health. Washington, DC: ACOG; 2005.

108. Mennella JA, Garcia-Gomez PL. Sleep disturbances after acute exposure to alcohol in mothers' milk. Alcohol. 2001;25:153-158. [PubMed: 11839458]

109. Mennella JA. Regulation of milk intake after exposure to alcohol in mothers' milk. Alcohol Clin Exp Res. 2001;25:590-593. [PubMed: 11329500]

110. Davidson S, Alden L, Davidson P. Changes in alcohol consumption after childbirth. J Adv Nurs. 1981;6:195-198. [PubMed: 6909224]

111. Pepino MY, Mennella JA. Advice given to women in Argentina about breast-feeding and the use of alcohol. Rev Panam Salud Publica. 2004;16:408-414. [PubMed: 15673483]

112. Mennella JA, Pepino MY. Biphasic effects of moderate drinking on prolactin during lactation. Alcohol Clin Exp Res. 2008;32:1899-1908. [PubMed: 18715274]

113. Mennella JA, Beauchamp GK. The transfer of alcohol to human milk-Effects on flavor and the infant's behavior. N Engl J Med. 1991;325:981-985. [PubMed: 1886634]

114. Ornoy A, Ergaz Z. Alcohol abuse in pregnant women: effects on the fetus and newborn, mode of action and maternal treatment. Int J Environ Res Public Health. 2010;7:364-379. [PubMed: 20616979] 


\section{Fetal Alcohol Spectrum Disorder can include:}

- Abnormal facial features, such as a smooth philtrum

- Small head size

- Shorter-than-average height

- Low body weight

- Poor coordination

- Hyperactive behavior

- Difficulty with attention

- Poor memory

- Difficulty in school (especially with math)

- Learning disabilities

- Speech and language delays

- Intellectual disability or low IQ

- Poor reasoning and judgment skills

- Sleep and sucking problems as a baby

- Vision or hearing problems

FIGURE 1.

Signs and symptoms of fetal alcohol syndrome disorder. ${ }^{43,44}$ IQ indicates intelligence quotient. 
TABLE 1.

\begin{tabular}{|c|c|c|}
\hline \multirow{2}{*}{ 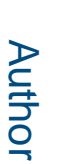 } & \multicolumn{2}{|l|}{ Alcoholic Drink-Equivalents ${ }^{13}$} \\
\hline & Drink Description & Drink Equivalent \\
\hline & \multicolumn{2}{|l|}{ Beer, beer coolers, and malt beverages } \\
\hline & $12 \mathrm{fL} \mathrm{oz}$ at $4.2 \%$ alcohol & 0.8 \\
\hline$\frac{c}{c}$ & $12 \mathrm{fL} \mathrm{oz}$ at $5 \%$ alcohol & 1 \\
\hline ? & $16 \mathrm{fL} \mathrm{oz}$ at $5 \%$ alcohol & 1.3 \\
\hline \multirow[t]{6}{*}{$\overline{\bar{\sigma}}$} & $12 \mathrm{fL} \mathrm{oz}$ at $7 \%$ alcohol & 1.4 \\
\hline & $12 \mathrm{fL} \mathrm{oz}$ at $9 \%$ alcohol & 1.8 \\
\hline & \multicolumn{2}{|l|}{ Wine } \\
\hline & $5 \mathrm{fL} \mathrm{oz}$ at $12 \%$ alcohol & 1 \\
\hline & $9 \mathrm{fL} \mathrm{oz}$ at $12 \%$ alcohol & 1.8 \\
\hline & $5 \mathrm{fL} \mathrm{oz}$ at $15 \%$ alcohol & 1.3 \\
\hline I & $5 \mathrm{fL} \mathrm{oz}$ at $17 \%$ alcohol & 1.4 \\
\hline ح่ & \multicolumn{2}{|l|}{ Distilled spirits } \\
\hline & $1.5 \mathrm{fL} \mathrm{oz} 80$ proof distilled spirits ( $40 \%$ alcohol) & 1 \\
\hline & Mixed drink with $>1.5 \mathrm{fL} \mathrm{oz} 80$ proof distilled spirits ( $40 \%$ alcohol) & $>1$ \\
\hline
\end{tabular}

